\title{
Adesão ao Tratamento por Cuidadores de Crianças e Adolescentes Soropositivos para o HIV ${ }^{1}$
}

\author{
Caroline Mota Branco Salles ${ }^{2}$ \\ Universidade de Brasília \\ Eleonora Arnaud Pereira Ferreira \\ Universidade Federal do Pará \\ Eliane Maria Fleury Seidl \\ Universidade de Brasilia
}

\begin{abstract}
RESUMO - Objetivou-se investigar o padrão de adesão ao tratamento por cuidadores de crianças e adolescentes HIV positivos e identificar as estratégias de enfrentamento adotadas diante de estressores da soropositividade. Participaram 30 cuidadores e utilizou-se entrevista semiestruturada, Escala Modos de Enfrentamento de Problemas e prontuário clínico, este como fonte de dados secundários. Os cuidadores foram classificados em Grupo Adesão e Grupo Não-Adesão com base em seus relatos sobre condutas de uso dos medicamentos antirretrovirais e outros critérios. Vinte e cinco cuidadores foram incluídos no Grupo Adesão. Não se observaram diferenças significativas quanto ao enfrentamento entre os grupos, excetuando a busca de práticas religiosas/pensamento fantasioso. Os resultados dão subsídios para intervenções visando reduzir impactos psicossociais da soropositividade a cuidadores, crianças e adolescentes.
\end{abstract}

Palavras-chave: adesão ao tratamento; enfrentamento; HIV/aids; cuidadores; crianças e adolescentes.

\section{Adherence to Treatment by Caretakers of Seropositive Children and Adolescents}

\begin{abstract}
This study aimed to investigate the pattern of adherence of caregivers of HIV seropositive children and adolescents and to identify the coping strategies against the stressors of seropositivity. The 30 caregivers that participated in the study responded to a semi-structured interview and a scale of how to cope with problems. A clinical record was used as a secondary data source. The caregivers were classified in an adhesion group $(n=25)$ and non-adhesion group $(n=5)$, based on their behavior related to the use of antiretroviral medicaments and other criteria. No significant differences were found in coping strategies between the groups, except in the strategy based on religiosity/fantasy thinking. The results provide a basis for interventions aimed at reducing psychosocial impacts of HIV.
\end{abstract}

Keywords: adherence to treatment; coping; HIV/AIDS; caregivers; children and adolescents.

Na literatura da Psicologia da Saúde, estudos têm sido realizados com o objetivo de promover adesão ao tratamento e desenvolver habilidades de enfrentamento (coping) em pacientes acometidos por doenças crônicas (Abreu-Rodrigues \& Seidl, 2008; Chesney, Chambers, Taylor, Johnson, \& Folkman, 2003; Godin, Côté, Naccache, Lambert, \& Trottier, 2005). Segundo Clark e Becker (2003), um dos principais problemas no contexto das enfermidades crônicas é a não adesão, pois apesar da disponibilidade de recursos farmacológicos e terapêuticos, as pessoas muitas vezes não fazem uso desses recursos para seu próprio benefício e recuperação. Desse modo, entender o fenômeno adesão é uma tarefa complexa, uma vez que as medidas adotadas para verificar a correspondência entre o que é prescrito pelos profissionais e o que é praticado pelo paciente podem ser bastante diversificadas, dependendo do grau de complexidade da análise e dos objetivos de investigação (Rand \& Weeks, 1998). Nesse

1 Apoio CNPq.

2 Endereço institucional: Caroline Mota Branco Salles. Instituto de Psicologia da Universidade de Brasília, Campus Darcy Ribeiro, Brasília, DF, Brasil 70910-900. Email: cbranco@unb.br campo, o autorrelato é a principal forma de investigar e obter informações sobre a adesão dos pacientes, apesar das controvérsias e limitações que envolvem essa modalidade de avaliação da adesão (Faustino \& Seidl, 2010; Ferreira, 2001; Rand \& Weeks, 1998).

A literatura chama atenção para o fato de que a probabilidade do seguimento ou não seguimento do tratamento depende de fatores que vão além das características relacionadas ao paciente, pois depende de aspectos do próprio tratamento, da rede de apoio social e familiar e da equipe responsável pela condução terapêutica (Arruda \& Zannon, 2002; Ferreira, 2006; World Health Organization, 2003).

Estratégias de enfrentamento são definidas por Folkman, Lazarus, Gruen e De Longis (1986) como o conjunto de esforços utilizados pelo indivíduo para lidar com demandas estressoras que estão sobrecarregando ou excedendo os recursos pessoais. Apesar das diferenças existentes entre os modelos conceituais e explicativos do processo de enfrentamento (Aldwin, 1994; Lazarus \& Folkman, 1984), existem alguns pontos comuns entre essas abordagens, pois todas buscam responder como os indivíduos se adaptam a 
circunstâncias adversas ou a situações estressantes diante de estressores específicos; descrevem a reação dos indivíduos em situações nas quais há sobrecarga de seus recursos pessoais e relacionam o processo com a diminuição/eliminação dos efeitos negativos causados pelo estressor (Dell' Aglio, 2003).

$\mathrm{O}$ enfrentamento pode estar relacionado à focalização no problema, focalização na emoção ou na busca de suporte social, sendo que alguns instrumentos de medida têm sido desenvolvidos para esclarecer as estratégias utilizadas por cuidadores e pacientes no gerenciamento do tratamento. No Brasil, um dos instrumentos utilizados para avaliar esse construto é a Escala Modos de Enfrentamento de Problemas [EMEP] (Seidl, Tróccoli \& Zannon, 2001) que analisa respostas específicas diante de situações estressoras como, por exemplo, viver com HIV/aids.

Estudo conduzido por Seidl, Rossi, Viana, Meneses e Meireles (2005) investigou a adesão ao tratamento e o uso de estratégias de enfrentamento de cuidadores de crianças e adolescentes soropositivos. Os dados foram coletados por meio de entrevistas realizadas com os cuidadores responsáveis pelo tratamento, cuidadores primários, abordando as principais dificuldades relacionadas ao gerenciamento do tratamento e identificando diferentes estratégias usadas no enfrentamento da soropositividade. Os resultados mostraram, como modalidade de enfrentamento mais utilizada, a busca de práticas religiosas/pensamento fantasioso, seguida de enfrentamento focalizado no problema e busca de suporte social. Os resultados do estudo de Seidl et al. (2005) ainda revelaram dificuldades dos cuidadores relacionadas ao curso do tratamento, à revelação do diagnóstico na escola e à revelação do diagnóstico para a criança e adolescente. Esses resultados corroboram os da literatura internacional, ao apontar que famílias de crianças e de adolescentes soropositivos defrontam-se diariamente com uma rotina de vida repleta de estressores (Antle, Wells, Goldie, DeMatteo \& King, 2001), podendo trazer, como consequência, desarticulação da estrutura familiar (Wiener, Vasquez \& Battles, 2001), estresse e desajuste comportamental dos cuidadores (Lewis, 2001) e conflitos relacionados à revelação do diagnóstico no momento oportuno (Grecca, 2004; Instone, 2000).

Em relação às tentativas de controle do HIV/aids, desde a década de 1980 têm sido desenvolvidos programas de assistência médica e psicossocial para pacientes infectados pelo Vírus da Imunodeficiência Humana (HIV). Com o advento da terapia antirretroviral altamente potente, tem ocorrido queda na mortalidade e aumentado os índices de sobrevida desses pacientes (Chen, Hoy \& Lewin, 2007; Grecca, 2004). Nesse contexto, o estudo da adesão ao tratamento de pacientes soropositivos ganhou importância, e as variáveis socioculturais passaram a ser investigadas como relevantes para o entendimento dessa questão.

O tratamento em HIV/aids é estabelecido com base na combinação de medicamentos denominados de antirretrovirais (ARV). O desenvolvimento de novas combinações entre essas drogas, assim como de ARV mais potentes, tem proporcionado melhor qualidade de vida aos pacientes soropositivos. O regime de administração dos ARV é ajustado de acordo com a situação específica de cada paciente e os protocolos terapêuticos garantem prescrições seguras e eficazes (Brasil, 2008).
O nível de adesão ao tratamento em HIV/aids deve ser igual ou superior a $95 \%$, tendo como referência o número de comprimidos ingeridos em relação ao número de doses prescritas em um período de tempo, como a última semana ou o último mês. De acordo com a Organização Mundial de Saúde (Brasil, 2008; World Health Organization, 2003), cerca de um terço dos pacientes soropositivos apresenta níveis de adesão inferiores a 95\%, o que pode prejudicar a eficácia do tratamento e propiciar a ocorrência de resistência viral ou de falha terapêutica. Nesse contexto, comportamentos de não adesão são falhas episódicas no seguimento do tratamento (o paciente esquece-se de tomar doses da medicação por um dia ou atrasa o horário de ingestão eventualmente) ou recorrentes (ocorrência repetida de situações que prejudicam o uso dos medicamentos, ocasionando perdas de doses ou atrasos frequentes). Pode-se mencionar ainda a total interrupção do tratamento por conta própria, quando o paciente suspende por completo a ingestão dos medicamentos antirretrovirais.

O autorrelato tem sido a fonte principal para obtenção de dados sobre a conduta de adesão, fornecido pelo paciente ou seu cuidador com base em informações como a ingestão de medicamentos no último mês, na última semana ou nos três últimos dias, por exemplo, (Brasil, 2008; Seidl et al., 2005). A adesão em HIV/aids também pode ser avaliada pela investigação de indicadores objetivos, como dados oriundos de exames laboratoriais do paciente como a contagem de células de defesa (linfócitos T CD4) e a quantidade de vírus circulante no sangue (carga viral). O índice satisfatório de CD4 deve ser de pelo menos 350 células $/ \mathrm{mm} 3$, e a carga viral, a menor possível, denominada indetectável ou menor que 50 cópias por $\mathrm{mm}^{3}$ (Brasil, 2008).

Entre crianças e adolescentes soropositivos, a efetividade do tratamento antirretroviral não depende exclusivamente da adesão do próprio paciente, mas também da adesão do cuidador. Este precisará lidar com uma série de desafios e a literatura tem apontado que, quanto maior o conhecimento sobre as implicações do diagnóstico e do tratamento, maiores serão as chances de o cuidador desenvolver habilidades de enfrentamento favorecedoras da adesão (Brasil, 2008; Guerra \& Seidl, 2009; Klunklin \& Harrigan, 2002).

Seguindo o interesse da literatura internacional e da nacional relacionado ao tema da adesão ao tratamento e enfrentamento da soropositividade, a presente pesquisa objetivou descrever o padrão de adesão ao tratamento antirretroviral por cuidadores de crianças e adolescentes soropositivos atendidos em uma unidade pública de saúde da cidade de Belém, capital do Estado do Pará. O estudo teve ainda por objetivos: (1) identificar o perfil sociodemográfico dos cuidadores e aspectos relacionados à estrutura das famílias; (2) identificar fatores relacionados a condições clínicas, de desenvolvimento e de escolarização de crianças e adolescentes soropositivos; (3) investigar aspectos relacionados à revelação do diagnóstico para a criança e o adolescente; (4) identificar as variáveis que facilitam ou dificultam a adesão à terapia antirretroviral; e (6) investigar as estratégias de enfrentamento adotadas pelos cuidadores, visando estabelecer relações entre modalidades de enfrentamento e conduta de adesão. 


\section{Método}

Foi realizado um estudo descritivo, com delineamento transversal, por meio de entrevistas conduzidas com cuidadores primários de crianças e adolescentes soropositivos.

\section{Participantes}

Participaram do estudo trinta cuidadores primários de crianças e adolescentes infectados pelo HIV, 80\% ( $\mathrm{n}=24)$ deles por transmissão vertical. O número de participantes da pesquisa $(\mathrm{N}=30)$ representou $31 \%$ dos casos de crianças e adolescentes HIV positivos registrados na unidade de saúde pesquisada que, à época, totalizava 97 pacientes. Foram utilizados os seguintes critérios de inclusão para os participantes: (a) ser o cuidador primário da criança ou do adolescente ou, ainda, o responsável direto pelo gerenciamento do tratamento, podendo, assim, fornecer informações mais detalhadas sobre a rotina de vida e outros aspectos; (b) ter mais de 18 anos e habilidades de leitura e escrita, e (c) ter conhecimento e concordar com as condições descritas no Termo de Consentimento Livre e Esclarecido (TCLE).

Dos 30 cuidadores da amostra, $22(73,3 \%)$ eram do sexo feminino. O maior número de cuidadores era composto de mães, sendo que $60 \%$ dos cuidadores não eram pais biológicos da criança ou do adolescente, conforme mostra a Tabela 1.
Entre as 30 crianças e adolescentes estudados, 19 (66,3\%) eram do sexo feminino e $11(36,7 \%)$ do sexo masculino. A idade variava de dois a 14 anos, sendo a média equivalente a 6,8 anos (desvio-padrão $=3,58$ ). Os dados mostraram que $80 \%$ dos casos de infecção da criança e do adolescente pelo HIV ocorreram por transmissão vertical.

A coleta de dados foi realizada na Unidade de Referência Materno Infantil e Adolescente (UREMIA), localizada no município de Belém, Estado do Pará. A UREMIA possui um programa de atendimento ambulatorial direcionado a crianças e adolescentes soropositivos, que está incluído no Programa de Doenças Infecto-Parasitárias (DIP).

\section{Instrumentos}

Roteiro de entrevista com o cuidador: roteiro semiestruturado, contendo perguntas abertas e fechadas sobre aspectos sociodemográficos, clínicos e psicossociais de crianças e adolescentes soropositivos e de seus familiares, bem como sobre comportamentos de adesão ao tratamento em HIV/ aids, adaptado do roteiro desenvolvido por Seidl et al. (2005).

Escala Modos de Enfrentamento de Problemas - EMEP (Seidl et al., 2001): com 45 itens, agrupados em quatro fatores, relacionados a estratégias de enfrentamento focalizadas no problema ( 18 itens, alpha de Cronbach $=0,84$ ); estratégias

Tabela 1. Características sociodemográficas dos cuidadores $(\mathrm{N}=30)$.

\begin{tabular}{|c|c|c|c|}
\hline & Variáveis & Freqüência & $\%$ \\
\hline & 20 a 30 anos & 10 & 33,3 \\
\hline & 31 a 40 anos & 6 & 20 \\
\hline Idade & 41 a 50 anos & 5 & 16,7 \\
\hline & 51 a 60 anos & 5 & 16,7 \\
\hline & Mais de 61 anos & 4 & 13,3 \\
\hline \multirow{6}{*}{ Relação de parentesco com as crianças e/ou adolescentes } & Mãe & 9 & 30 \\
\hline & Pai & 3 & 10 \\
\hline & Avó/Avô/Bisavó & 9 & 30 \\
\hline & Tia & 5 & 16,7 \\
\hline & Irmã & 1 & 3,3 \\
\hline & Adoção ou sem grau de parentesco & 3 & 10 \\
\hline \multirow{5}{*}{ Escolaridade } & Analfabeto ou Ens Fund Incompleto & 18 & 60 \\
\hline & Ensino Fundamental Completo & 6 & 20 \\
\hline & Ensino Médio Incompleto & 3 & 10 \\
\hline & Ensino Médio Completo & 2 & 6,7 \\
\hline & Ensino Superior Incompleto & 1 & 3,3 \\
\hline \multirow{5}{*}{ Situação empregatícia } & Aposentado(a) & 4 & 13,3 \\
\hline & Desemp./Não está trabalhando & 12 & 40 \\
\hline & Nunca trabalhou & 7 & 23,4 \\
\hline & Trabalha por conta própria às vezes & 3 & 10 \\
\hline & Trabalha por conta própria regularmente & 4 & 13,3 \\
\hline \multirow{4}{*}{ Renda Familiar } & 1 Salário Mínimo (SM) & 9 & 30 \\
\hline & 2 a 3 SM & 15 & 50 \\
\hline & 4 a $5 \mathrm{SM}$ & 5 & 16,7 \\
\hline & 5 a $9 \mathrm{SM}$ & 1 & 3,3 \\
\hline
\end{tabular}


de enfrentamento focalizadas na emoção (15 itens, alpha de Cronbach $=0,81)$; busca de práticas religiosas/pensamentos fantasiosos ( 7 itens, alpha de Cronbach=0,74) e busca de suporte social ( 5 itens, alpha de $\mathrm{Cronbach}=0,70$ ). As respostas são dadas em escala Likert, de cinco pontos, que variam entre 1 (nunca faço isso) e 5 (faço isso sempre), cujo objetivo é analisar respostas específicas (estratégias de enfrentamento) diante de situações estressoras. Na aplicação foi usada uma escala visual para apoio à emissão das respostas à EMEP diante de dificuldades de entendimento do cuidador.

Como fonte de dados secundários, realizou-se consulta aos prontuários clínicos, que continham informações referentes a atendimentos e procedimentos médicos e resultados de exames (CD4 e carga viral).

\section{Procedimento}

Inicialmente, o projeto foi encaminhado ao Comitê de Ética e Pesquisa (CEP) local, sendo aprovada a sua realização. Os participantes foram convidados no serviço de saúde onde criança e adolescente realizavam acompanhamento médico. Feito o contato inicial com o cuidador e o consentimento para participar do estudo mediante a assinatura do TCLE, era introduzida a EMEP, de forma autoaplicada. Foi observado que alguns cuidadores apresentaram dificuldades para assinalar as respostas, devido à baixa escolaridade. Nesses casos, os itens eram lidos pela pesquisadora, com o cuidado de minimizar ao máximo a influência sobre as respostas. Após a aplicação da EMEP, iniciava-se a entrevista com o cuidador com base no roteiro semiestruturado. Por fim, foram coletados no prontuário dados referentes ao comparecimento às consultas agendadas e aos resultados de exames clínicos relativos à condição imunológica (linfócitos T CD4) e virológica (carga viral) da criança ou adolescente.

\section{Análise de dados}

As entrevistas foram transcritas e as respostas analisadas, segundo categorias predefinidas pelos autores (Tabela 2). $\mathrm{Na}$ categorização dos relatos, levou-se em consideração a ocorrência dos comportamentos de adesão ou não adesão, de acordo com o seguinte critério: o Grupo Adesão (GA) constituiu-se de cuidadores cujos relatos contemplaram pelo menos sete das nove categorias indicativas de adesão ao tratamento. O Grupo Não Adesão (GNA), por sua vez, foi formado de cuidadores que apresentaram autorrelato que correspondia a seis ou menos categorias relativas à adesão ao tratamento. A divisão de cuidadores entre GA e GNA teve como objetivo descrever as condutas de adesão, identificando aspectos facilitadores e limitadores desse processo.

$\mathrm{O}$ autorrelato, obtido mediante as respostas ao roteiro de entrevista, tornou-se a principal medida de adesão ao tratamento na presente pesquisa. Dois dos critérios para a formação dos grupos GA e GNA foram oriundos de dados secundários, obtidos da análise do prontuário dos pacientes: (1) indicadores imunológicos e virológicos decorrentes dos resultados de exames dos níveis de linfócitos T CD4 e da carga viral plasmática da criança ou adolescente; (2) dados referentes ao comparecimento às consultas agendadas.

Em relação à EMEP, os escores foram obtidos do cálculo da média aritmética para cada um dos quatro fatores (Seidl \& et al., 2001). O programa Statistical Package for Social Sciences (SPSS), versão 13.0, foi utilizado nas análises estatísticas descritivas das variáveis, com o uso de técnicas como qui-quadrado e teste t de Student.

\section{Resultados}

A média do CD4 foi de 433,9 células $/ \mathrm{mm}^{3}$ (mínimo=108; máximo=850; desvio-padrão=204,9). Em relação à carga viral, registrou-se a média de 99.739,3 cópias (mínimo=850; máximo=1.100.000; desvio-padrão=214.763,81).

Quanto às condições de desenvolvimento, 18 cuidadores (60\%) relataram ocorrência de problemas de desenvolvimento na história passada ou atual da criança ou do adolescente. Tais problemas foram agrupados de acordo com as semelhanças dos relatos e envolveram queixas relacionadas a déficits de atenção, desinteresse, dificuldade de concentração, isolamento social e agitação (classificadas como problemas comportamentais=três ocorrências); queixas relacionadas a problemas de visão, déficits no crescimento e nutricionais, baixo peso e problemas auditivos (classificadas como problemas físico-orgânicos=oito ocorrências); problemas de leitura, atraso escolar e dificuldades na fala (classificadas como problemas de aprendizagem=três ocorrências) e queixas relacionadas à restrição a andar, a movimentar-se, a sentar-se, a sustentar o corpo e a locomover-se (classificadas como problemas motores $=$ quatro ocorrências). Em todos os casos, os cuidadores atribuíram o surgimento de problemas de desenvolvimento como consequência de complicações decorrentes do HIV/aids. Os cuidadores relataram que a partir do início do tratamento e melhora da adesão houve progressos em relação às queixas citadas.

Vinte por cento $(n=6)$ das crianças e adolescentes da amostra tinham conhecimento sobre seu próprio diagnóstico, segundo o relato dos cuidadores. A revelação se deu para duas crianças e quatro pré-adolescentes (idade entre dez e 13 anos). Não houve informação sobre o diagnóstico para 15 pacientes, sendo dez crianças (entre cinco e nove anos) e cinco pré-adolescentes e adolescentes, segundo os entrevistados. Na Tabela 3, mostra-se a relação entre conhecimento do diagnóstico, faixa etária e sexo das crianças e adolescentes. As crianças entre dois e cinco anos incompletos foram excluídas dessa análise pelo fato de a faixa etária reduzida impossibilitar/desaconselhar a revelação do diagnóstico até aquele momento.

Dos 30 cuidadores, 22 (73,3\%) relataram não ter planejado a revelação do diagnóstico à criança ou ao adolescente. Oito cuidadores $(26,7 \%)$ relataram ter feito algum tipo de planejamento para o processo de revelação de situações futuras. A atitude dos cuidadores para com a revelação do diagnóstico foi expressa em falas como: "ele é muito novo para saber" ou "quando ela ficar mais velha eu conto".

Setenta por cento do número total de crianças e adolescentes em idade escolar (21 com idade acima de cinco anos) estudava no momento da coleta de dados. Os cuidadores das 
Tabela 2. Descrição das categorias de análise e critérios para inclusão dos cuidadores, a partir de seus relatos verbais, no Grupo Adesão ou Não Adesão.

\begin{tabular}{|c|c|c|}
\hline Categoria & Grupo Adesão & Grupo Não Adesão \\
\hline $\begin{array}{l}\text { Conhecimento sobre a quanti- } \\
\text { dade de ARV prescritos }\end{array}$ & $\begin{array}{l}\text { Conhece o número de ARV prescritos e descreve } \\
\text { apropriadamente a rotina de administração dos } \\
\text { medicamentos }\end{array}$ & $\begin{array}{l}\text { Desconhece o número de ARV prescritos e des- } \\
\text { creve inapropriadamente a rotina de administração } \\
\text { dos medicamentos }\end{array}$ \\
\hline $\begin{array}{l}\text { Conhecimento da história de } \\
\text { uso dos ARV }\end{array}$ & $\begin{array}{l}\text { Conhece a história de administração dos medica- } \\
\text { mentos antirretrovirais }\end{array}$ & $\begin{array}{l}\text { Desconhece a história de administração dos medi- } \\
\text { camentos antirretrovirais }\end{array}$ \\
\hline $\begin{array}{l}\text { História de adesão } \\
\text { ao tratamento }\end{array}$ & $\begin{array}{l}\text { Seguiu o tratamento sem interrupções ou com } \\
\text { interrupções causadas por motivos externos à ação } \\
\text { do cuidador }\end{array}$ & $\begin{array}{l}\text { Interrompeu o tratamento por uma ou mais vezes, } \\
\text { por responsabilidade do cuidador }\end{array}$ \\
\hline $\begin{array}{l}\text { Dificuldades para seguir o } \\
\text { tratamento }\end{array}$ & $\begin{array}{l}\text { Relata pouca ou nenhuma dificuldade para seguir a } \\
\text { prescrição do tratamento e utiliza estratégias para } \\
\text { enfrentar a situação }\end{array}$ & $\begin{array}{l}\text { Relata muitas e/ou extremas dificuldades para } \\
\text { seguir o tratamento e utiliza soluções parciais (ou } \\
\text { não utiliza) para enfrentar situação }\end{array}$ \\
\hline Auto-avaliação da adesão & $\begin{array}{l}\text { Descreve a auto-avaliação da adesão como boa ou } \\
\text { muito boa e aponta justificativas para o desempe- } \\
\text { nho de adesão }\end{array}$ & $\begin{array}{l}\text { Descreve a auto-avaliação da adesão como regular, } \\
\text { ruim ou péssima e aponta justificativas para o } \\
\text { desempenho de adesão }\end{array}$ \\
\hline $\begin{array}{l}\text { Nível de participação do } \\
\text { paciente no tratamento }\end{array}$ & $\begin{array}{l}\text { Identifica comportamentos de participação da } \\
\text { criança e/ou adolescente no próprio tratamento, } \\
\text { favorecendo a adesão do cuidador }\end{array}$ & $\begin{array}{l}\text { Identifica comportamentos de participação ou não- } \\
\text {-participação da criança e adolescente no próprio } \\
\text { tratamento, diminuindo a adesão do cuidador }\end{array}$ \\
\hline $\begin{array}{l}\text { Informações gerais sobre o } \\
\text { tratamento }\end{array}$ & $\begin{array}{l}\text { Descreve informações sobre o tratamento e rotina } \\
\text { de vida da criança e/ou adolescente que não alte- } \\
\text { ram a conduta de adesão }\end{array}$ & $\begin{array}{l}\text { Descreve informações relacionadas ao tratamento } \\
\text { e rotina de vida da criança e/ou adolescente que } \\
\text { alteram a conduta de adesão }\end{array}$ \\
\hline $\begin{array}{l}\text { Comparecimento às } \\
\text { consultas }\end{array}$ & Comparece regularmente às consultas agendadas & $\begin{array}{l}\text { Não comparece com regularidade às consultas } \\
\text { agendadas }\end{array}$ \\
\hline $\begin{array}{l}\text { Resultados de exames } \\
\text { laboratoriais }\end{array}$ & $\begin{array}{l}\text { A criança/adolescente apresenta resultados satisfa- } \\
\text { tórios nos exames de níveis de linfócitos T CD4 e } \\
\text { de carga viral, segundo parâmetros do Ministério } \\
\text { da Saúde }\end{array}$ & $\begin{array}{l}\text { A criança/adolescentes apresenta resultados in- } \\
\text { satisfatórios nos exames de níveis de linfócitos } \\
\text { T CD4 e de carga viral, segundo parâmetros do } \\
\text { Ministério da Saúde }\end{array}$ \\
\hline
\end{tabular}

Tabela 3. Conhecimento do diagnóstico, faixa etária e sexo de crianças e adolescentes soropositivos $(\mathrm{n}=21)^{*}$.

\begin{tabular}{|c|c|c|c|c|c|}
\hline \multirow{3}{*}{$\begin{array}{l}\text { Conhecimento do diagnóstico pela } \\
\text { criança/adolescente soropositivo(a) }\end{array}$} & \multicolumn{4}{|c|}{ Faixa Etária } & \multirow{3}{*}{ Total } \\
\hline & \multicolumn{2}{|c|}{5 a 9 anos } & \multicolumn{2}{|c|}{10 a 14 anos } & \\
\hline & $\mathrm{F}$ & $\mathrm{M}$ & $\mathrm{F}$ & $\mathrm{M}$ & \\
\hline Não sabe & 9 & 1 & 3 & 2 & 15 \\
\hline Sabe & 1 & 1 & 3 & 1 & 6 \\
\hline Total & 10 & 2 & 6 & 3 & 21 \\
\hline
\end{tabular}

* Nove crianças na faixa etária de 2 a 5 anos incompletos não foram incluídas na análise

cinco crianças em idade escolar que não estavam estudando na época da pesquisa relataram diversos motivos para não terem matriculado as crianças na escola. Tais motivos envolveram: (1) complicações decorrentes do tratamento; (2) consequências trazidas pela revelação do diagnóstico na escola; (3) indisponibilidade de vagas em função do diagnóstico revelado; e (4) esquiva de situações que pudessem trazer adversidades para a administração do tratamento, como incompatibilidade do horário escolar com o horário da medicação.
Dos 30 cuidadores entrevistados, 25 (83,3\%) foram classificados como GA e cinco $(16,7 \%)$ como GNA, de acordo com os critérios citados anteriormente. A análise da associação entre variáveis sociodemográficas e padrão de adesão ao tratamento mostrou que o número maior de moradores na residência (acima de seis) esteve relacionado à baixa adesão $(\mathrm{p}<0,001)$. Outras variáveis sociodemográficas dos cuidadores (como sexo, faixa etária, situação conjugal e escolaridade) foram investigadas, não sendo encontrada associação significativa com as condições adesão e não adesão. 
Dos trinta cuidadores, $16(53,3 \%)$ relataram ter interrompido o tratamento em alguma situação anterior à pesquisa, e 14 deles (46,7\%) negaram qualquer ocorrência de interrupção. No momento da coleta de dados, nenhum cuidador relatou o abandono do tratamento. A análise estatística efetuada revelou associação significativa entre as modalidades de grupo (GA e GNA) e história de interrupção do tratamento pelos cuidadores $(p=0,03)$ : no GNA os cinco cuidadores haviam interrompido o tratamento em situações anteriores $(100 \%)$ e, no GA, 11 , ou seja, menos de $44 \%$, relataram algum tipo de interrupção, mesmo que momentânea.

Dezoito cuidadores relataram que, diante de dificuldades no manejo da rotina do tratamento, sempre ou quase sempre utilizaram alguma estratégia para que o paciente tomasse o medicamento, indicando que, mesmo diante da oposição da criança ou do adolescente, eles conseguiram seguir o tratamento sem interrupções.

Relativamente às estratégias de enfrentamento, investigou-se a relação entre aquelas relatadas pelos cuidadores e o padrão de adesão ao tratamento. Na Tabela 4 pode-se verificar que o uso de estratégias de enfrentamento foi diferenciado entre os grupos: no Grupo Adesão a média mais alta $(4,33)$ foi encontrada para o fator busca de práticas religiosas/pensamento fantasioso e para o Grupo Não adesão, a média mais alta verificada $(3,94)$ foi para enfrentamento focalizado no problema. Observou-se que não houve diferença estatisticamente significativa entre os grupos quanto às estratégias de enfrentamento utilizadas, exceto no que se refere à estratégia busca de práticas religiosas/pensamentos fantasiosos $(\mathrm{p}=0,05)$. Vale referir ainda que, levando em conta o conjunto dos participantes, a focalização no problema e a busca de práticas religiosas/pensamento fantasioso foram as estratégias mais usadas. Estratégias centradas na emoção e na busca de apoio social obtiveram as médias mais baixas, evidenciando, nos dois grupos, o uso limitado dessas modalidades de enfrentamento entre os cuidadores.

\section{Discussão}

Os avanços da terapia antirretroviral na área do HIV/aids vêm proporcionando melhores condições de vida e de saúde para pacientes soropositivos, permitindo caracterizá-la como enfermidade crônica (Brasil, 2008; Chen, Hoy \& Lewin, 2007). A literatura tem demonstrado que, entre pacientes crônicos, o auxílio do cuidador aumenta a probabilidade do seguimento do protocolo terapêutico (Arruda \& Zannon, 2002). A abordagem do cuidador torna-se, assim, de suma importância, pois, quando o paciente não possui autonomia suficiente para gerenciar o próprio tratamento, é o cuidador quem fica responsável por colocar o comportamento do paciente sob controle das contingências relativas ao tratamento.

Os dados ora apresentados foram organizados de forma a entender como aspectos do contexto de vida e do tratamento de famílias que convivem com a soropositividade facilitaram (ou dificultaram) o seguimento do tratamento antirretroviral. Assim, neste estudo, buscou-se compreender a adesão ao tratamento como um processo contextual, vinculado ao seguimento das regras fornecidas pela equipe de saúde.

Os resultados revelaram que as crianças e os adolescentes contavam, em grande parte, com cuidadores que não eram seus pais biológicos. Verifica-se na literatura que muitas famílias, cujas crianças ou adolescentes são soropositivos para o HIV, podem passar por processos de reorganização do núcleo familiar, quando um dos pais biológicos (ou os dois) vem a falecer em decorrência das complicações advindas da aids (Seidl et al., 2005; Wiener et al., 2001). O impacto trazido por esse tipo de reorganização familiar foi um dado relevante para o nível de adesão ao tratamento dos cuidadores. De acordo com os resultados, o número maior de pessoas que morava na residência esteve associado a dificuldades de adesão. É possível que o convívio com muitas pessoas em uma mesma residência, provavelmente em condição de pobreza, tenha gerado situações concorrentes à adesão e acarretado contextos adversos que dificultavam o uso dos medicamentos.

Quanto à conduta de adesão ao tratamento da amostra estudada, todos os cuidadores do GA relataram seguir o tratamento por conhecerem as implicações trazidas pela adesão e pela não adesão. Os cuidadores do GNA tiveram dificuldades nos relatos fornecidos sobre as consequências de seguir ou não seguir o tratamento, demonstrando, assim, imprecisão na descrição verbal dos comportamentos exigidos para uma adesão adequada.

Na perspectiva da psicologia da saúde, o ajustamento psicológico em condição de cronicidade pode ocorrer pelo uso de determinadas estratégias de enfrentamento. Este é um processo cognitivo e comportamental que caracteriza as formas de lidar com uma sobrecarga de estressores (Dell'Aglio, 2003). No presente trabalho utilizou-se de um instrumento para investigar as estratégias de enfrentamento adotadas pelos cuidadores diante da soropositividade da criança ou do adolescente, além dos relatos obtidos de entrevista. Pelas respostas fornecidas pelos cuidadores, pôde-se observar maior predomínio de busca de práticas religiosas ou de pensamentos fantasiosos, podendo significar que, diante de dificuldades e de situações estressoras advindas da soropositividade, os cuidadores adotavam estratégias "mágicas" para lidar com

Tabela 4. Médias e Desvios-Padrão dos Fatores da EMEP dos Grupos Adesão ( $n=25)$ e Não-Adesão (n= 5).

\begin{tabular}{ccccc}
\hline Grupo & $\begin{array}{c}\text { Fator 1: } \\
\text { Estratégias focalizadas } \\
\text { no problema }\end{array}$ & $\begin{array}{c}\text { Estratégias focalizadas } \\
\text { na emoção }\end{array}$ & $\begin{array}{c}\text { Fator 3: } \\
\text { Busca de práticas re- } \\
\text { ligiosas/pensamentos } \\
\text { fantasiosos }\end{array}$ & $\begin{array}{c}\text { Fator 4: } \\
\text { Busca de suporte social }\end{array}$ \\
\hline Adesão & $3,96 \pm 0,42$ & $2,30 \pm 0,58$ & $4,33 \pm 0,47$ & $2,53 \pm 0,89$ \\
\hline Não-adesão & $3,94 \pm 0,42$ & $2,33 \pm 0,59$ & $3,85 \pm 0,60$ & $2,68 \pm 0,70$ \\
\hline Teste t & 0,89 & 0,93 & 0,05 & 0,74 \\
\hline
\end{tabular}


uma situação incontrolável decorrente da impossibilidade de cura para a infecção pelo HIV, por exemplo. Tal conclusão pode ser ilustrada por relatos como: "Sei que Deus vai mandar uma vacina"; "Eu rezo pra Deus porque sei que Ele é poderoso pra dar tudo para a gente"; "Peço a Deus um milagre para que meu neto seja curado". Esses resultados confirmaram aqueles observados no estudo conduzido por Seidl et al. (2005).

Observou-se, também o uso frequente de estratégias focalizadas no problema, o que está em consonância com o fato de a maioria dos cuidadores ter relatado adesão adequada. Condutas de adesão caracterizam ações de aproximação relativas ao estressor, no caso a soropositividade, que podem ser categorizadas como focadas no problema.

Quanto a postergar a revelação do diagnóstico, a literatura tem apontado que o desconhecimento do diagnóstico pela criança ou adolescente pode trazer consequências negativas como déficits em autoestima e isolamento social (Instone, 2000). Os resultados indicaram que o diagnóstico de soropositividade era desconhecido por $70 \%$ dos pacientes. Desses, cerca de 35\% eram adolescentes entre 10 e 14 anos. Esses dados revelam as dificuldades que os cuidadores têm apresentado para revelar o diagnóstico de soropositividade para as crianças e adolescentes, conforme registro na literatura (Guerra \& Seidl, 2009; Seidl et al., 2005), indicando a importância da abordagem do tema por equipes interdisciplinares. Uma forte implicação da não revelação do diagnóstico para a adesão refere-se às barreiras para propiciar atendimento específico para a criança ou adolescente, pois, se eles desconhecem a condição ou a enfermidade que os acomete, não poderá usufruir do atendimento e da atenção da equipe para questões como autocuidado, enfrentamento e adesão.

Os níveis de CD4 da maioria dos pacientes foram satisfatórios, indicando boas condições imunológicas e maior probabilidade de resistência a doenças ou infecções oportunistas. No entanto, os dados secundários indicaram que nenhum dos participantes estava com carga viral indetectável. Tal dado sugere a ocorrência de eventuais falhas na adesão, pois carga viral indetectável é o melhor indicador de adesão plena ou igual a 95\% (Brasil, 2008). Sugere-se que estudos futuros investiguem a perda de comprimidos, de esquema terapêutico prescritos, tendo como referência o dia ou a semana anterior à entrevista, para que a conduta de adesão ao tratamento seja investigada com maior precisão.

Finalizando, a presente pesquisa objetivou descrever o padrão de adesão ao tratamento de cuidadores de crianças e adolescentes soropositivos de uma unidade de referência em atendimento pediátrico do Pará. Ao descrever a condição de vida dessas famílias e ao inquiri-las sobre a conduta de adesão, mediante os instrumentos empregados, acredita-se que o presente trabalho pôde contribuir para a ampliação da literatura sobre adesão ao tratamento antirretroviral. Indica-se, para trabalhos futuros, a investigação acerca do papel de instruções sobre o seguimento do tratamento, valorizando ainda o relato do próprio paciente em relação ao do cuidador, uma vez que é possível supor que o relato deste pode perder fidedignidade com o aumento da faixa etária da população analisada, como os adolescentes, já que estes podem gerenciar seu próprio tratamento.

\section{Referências}

Abreu-Rodrigues, M., \& Seidl, E. M. F. (2008). A importância do apoio social em pacientes coronarianos. Paidéia, 18, 279-288.

Aldwin, C. M. (1994). Stress, coping and development: an integrative perspective. London: Guilford Press.

Antle, B. J., Wells, L. M., Goldie, R. S., DeMatteo D., \& King, S. M. (2001). Challenges of parenting for families living with HIV/AIDS. Social Work, 46, 159-169.

Arruda, P. M., \& Zannon, C. M. L. C. (2002). Tecnologia comportamental em saúde. Adesão ao tratamento pediátrico da doença crônica: evidenciando o desafio enfrentado pelo cuidador. Santo André: ESETec.

Brasil. Ministério da Saúde. Programa Nacional de DST e Aids (2008). Manual de adesão ao tratamento para pessoas vivendo com HIV e Aids. Brasília: Ministério da Saúde.

Chen, L. F., Hoy, J., \& Lewin, S. R. (2007). Ten years of highly active antiretroviral therapy for HIV infection. Medical Journal of Australia, 186(3), 146-151.

Chesney, M. A., Chambers, D. B., Taylor, J. M., Johnson, L. M., \& Folkman, S. (2003). Coping effectiveness training for men living with HIV: results from a randomized clinical trial testing a group-based intervention. Psychosomatic Medicine, 65, 1038-1046.

Clark, N. M., \& Becker, M. H. (2003). Theoretical models for improving adherence and disease management. In S. A. Shumaker, E. B. Schron, J. K. Ockene \& W. L. Macbee (Eds.), The Handbook of Health Behavior Change (pp. 5-32). NY: Springer Publishing Company.

Dell'Aglio, D. D. (2003). O processo de coping em crianças e adolescentes: adaptação e desenvolvimento. Temas em Psicologia da SBP, 11(1), 38-45.

Faustino, Q. M., \& Seidl, E. M. F. (2010). Intervenção cognitivocomportamental e adesão ao tratamento de pessoas vivendo com HIV/aids. Psicologia: Teoria e Pesquisa, 26(1), 121-130.

Ferreira, E. A. P. F. (2001). Adesão ao tratamento em portadores de diabetes mellitus: efeitos de um treino em análise de contingência sobre comportamentos de autocuidado. Tese de Doutorado, Universidade de Brasília. Brasília.

Ferreira, E. A. P. F. (2006). Adesão ao tratamento em psicologia pediátrica. In M. A. Crepaldi, M. B. M. Linhares \& G. B. Peroza (Eds.), Temas em Psicologia Pediátrica (pp. 112-144). São Paulo: Casa do Psicólogo.

Folkman, S., Lazarus, R. S., Gruen, R. J., \& De Longis, A. (1986). Appraisal, coping, health status and psychological symptons. Journal of Personality and Social Psychology, 50, 571-579.

Godin, G., Côté, J., Naccache, H., Lambert, L. D., \& Trottier, S. (2005). Prediction of adherence to antiretroviral therapy: a one-year longitudinal study. AIDS Care, 17(4), 493-504.

Grecca, K. R. R. (2004). Variáveis identificadas na revelação do diagnóstico de HIV/Aids para crianças e adolescentes. Dissertação de Mestrado, Pontifícia Universidade Católica de Campinas, Campinas.

Guerra, C. P. P., \& Seidl, E. M. F. (2009). Crianças e adolescentes com HIV/aids: revisão de estudos sobre revelação do diagnóstico, adesão e estigma. Paidéia, 19(42), 59-65.

Instone, S. L. (2000). Perceptions of children with HIV infection when not told for so long: Implications for disclosure. Journal of Pediatric Health Care, 14, 235-243. 
Klunklin, P., \& Harrigan, R. C. (2002). Child-rearing practices of primary caregivers of HIV-infected children: an integrative review of the literature. Journal of Pediatric Nursing, 17, 289-296.

Lazarus, R. S., \& Folkman, S. (1984). Stress, appraisal, and coping. New York: Springer.

Lewis, S. Y. (2001). Commentary: coping over the long haul: understanding and supporting children and families affected by HIV disease. Journal of Pediatric Psychology, 26, 359-361.

Rand, C. S., \& Weeks, K. (1998). Measuring adherence with medication regimens in clinical care and research. In S. A. Shumaker, E. B. Schron, J. K. Ockene \& W. L. Macbee (Eds.), The Handbook of Health Behavior Change (pp. 114-132). New York: Springer Publishing Company,

Seidl, E. M. F., Rossi, W. S., Viana, K. F., Meneses, A. K. F., \& Meireles, E. (2005). Crianças e adolescentes vivendo com HIV/ aids e suas famílias: aspectos psicossociais e enfrentamento. Psicologia: Teoria e Pesquisa, 21(3), 279-288.
Seidl, E. M. F., Tróccoli, B. T., \& Zannon, C. M. L. C. (2001). Análise fatorial de uma medida de estratégias de enfrentamento. Psicologia: Teoria e Pesquisa, 17(3), 225-234.

Wiener, L. S., Vasquez, M. J. P., \& Battles, H. B. (2001). Brief report: fathering a child living with HIV/AIDS: Psychosocial adjustment and parenting stress. Journal of Pediatric Psychology, 26, 353-358.

World Health Organization (2003). Adherence to long term therapies. Evidence for action. Switzerland: WHO.

Recebido em 23.10.2009

Primeira decisão editorial em 22.07.2010

Versão final em 30.08.2010

Aceito em 08.02.2011 